\title{
Artemisia annua increases resistance to heat and oxidative stresses, but has no effect on lifespan in Caenorhabditis elegans
}

\author{
Seung-Il OH${ }^{1}$, Jun-Sung $\mathrm{KIM}^{1}$, Chul-Kyu KIM${ }^{1}$, Sun Shin $\mathrm{YI}^{2}$, Sung-Jo KIM ${ }^{3}$, Sang-Kyu PARK ${ }^{1 *}$
}

\begin{abstract}
It is suggested that oxidative stress induced by cellular reactive oxygen species is one of the major causal factors of aging. The effect of dietary supplementation of anti-oxidants on response to environmental stressors and lifespan has been studied in various model organisms. In the present study, we examine the effect of Artemisia annua extract on resistance to oxidative, heat, and ultraviolet stresses in the nematode Caenorhabditis elegans. Artemisia annua significantly increases survival under oxidative and heat stresses, however has no effects in response to ultraviolet stress. Then, we measured the in vivo changes in expression of stress-responsive genes by Artemisia annua using green fluorescence protein. The expression of $h s p-16.2$, known to be involved in response to heat stress, is significantly increased by Artemisia annua supplementation. An anti-oxidant gene, sod-3, was also up-regulated by Artemisia annua. However, both mean and maximum lifespan of Caenorhabditis elegans was not altered by dietary supplementation of Artemisia annua. These findings indicate that Artemisia annua confers health-promoting effects through increasing the resistance to environmental stressors and has no effect on lifespan in C. elegans. Our study suggests that Artemisia аппиа can be used for the development of novel natural therapeutics for diseases caused by environmental stressors.
\end{abstract}

Keywords: Artemisia annua; oxidative stress; heat stress; lifespan; C. elegans.

Practical Application: This study shows Artemisia annua has an anti-stress activity and induces stress-responsive genes in vivo. These results provide scientific backgrounds necessary for the extension of the therapeutic applications of $A$. annua.

\section{Introduction}

The free radical theory of aging suggests that the age-dependent accumulation of oxidative damage induced by free radicals is the main cause of normal aging (Harman, 1956). Reactive oxygen species (ROS) are produced as a byproduct of normal cellular metabolism and main free radicals in cells. To prevent ROS-induced oxidative damage, cells have evolved anti-oxidant defense systems. Cellular anti-oxidant defense systems are composed of enzymatic and non-enzymatic defense systems. Enzymatic defense systems utilize cellular anti-oxidant enzymes, including catalase (CAT), superoxide dismutase (SOD), glutathione peroxidase, and so on, to transform hyperactive ROS into stable compounds (Sohal et al., 1995; Wei \& Lee, 2002). In addition, cellular anti-oxidants scavenge cellular ROS non-enzymatically (Miquel, 2001). However, ROS that escape anti-oxidant defense systems can cause oxidative damage in cellular macromolecules, such as DNA, proteins, and lipids. The accumulation of oxidative damage is positively associated with an organism's chronological age and known to be involved with the incidence of many age-related diseases (Sohal \& Weindruch, 1996).

Studies have shown that the genetic or nutritional interventions modulating cellular anti-oxidant defense systems can affect the health, as well as lifespan of many experimental organisms. In Drosophila melanogaster, transgenic animals overexpressing both SOD and CAT have increased resistance to oxidative stress and lifespan (Orr \& Sohal, 1992). Induction of the $\mathrm{Cu} / \mathrm{Zn}$ SOD transgene expression also confers longevity phenotype in Drosophila melanogaster (Sun \& Tower, 1999). In mice, overexpression of CAT induces increased resistance to hydrogen peroxide (Chen et al., 2004). In contrast, heterozygote knockout of SOD2 leads to increased oxidative damage and premature induction of apoptosis in mice (Kokoszka et al., 2001). Supplementation with anti-oxidants also modulates the response to oxidative stress and lifespan in model organisms. Supplementation of N-acetyl-L-cysteine confers increased resistance to various environmental stressors and longevity phenotype in C. elegans (Oh et al., 2015). Interestingly, worms grown in media prepared with electrolyzed reduced water, known to have a strong anti-oxidant activity, have increased resistance to oxidative stress and extended lifespan (Park et al., 2012; Park \& Park, 2013). Treatment with vitamin E prevents age-related decline of cognitive function and improves mitochondrial function, but fails to extend lifespan in mammals (Fukui et al., 2002; Lipman et al., 1998; Navarro et al., 2005). Therefore, the effects of anti-oxidants on response to stressors and lifespan seems to depend on the in vivo activity of each anti-oxidant.

Artemisia annua (A. апnua) is an annual plant used as a therapeutic medicine for various diseases in Korea. The most well-known bio-activity of $A$. annua is anti-malaria activity (Song et al., 2016). In addition, $A$. annua also has anti-imflammatory, anti-cancer, and anti-obesity activities (Ho et al., 2014). It is 
suggested that the polyphenol components of A. annua are responsible for those pharmacological activities. Since polyphenols are strong anti-oxidants, a number of studies focus on revealing of health-promoting activities of plant polyphenols. In the present study, we examine the effects of dietary supplementation of A. annua on health and lifespan using C. elegans as a model system. Response to environmental stressors, including heat stress, ultraviolet (UV) irradiation, and oxidative stress, was monitored in vivo. The effects of $A$. annua on the expression of stress-responsive genes was determined using green fluorescent protein (GFP). Then, we measured the effects of $A$. annua on the lifespan of C. elegans.

\section{Materials and methods}

\subsection{Worm strains and culture}

The wild-type N2 CGCb strain and two GFP-expressing strains, CL2070 (dvIs70 [ $P_{h s p-16.2}:: \mathrm{GFP}$, rol-6]) and CF1553 (muIs84 [ $P_{\text {sod- } 3}:$ GFP, rol-6]), were purchased from the C. elegans Genetics Center (CGC, Minneapolis, USA). The worms were maintained on nematode growth media (NGM) plates, which contains $25 \mathrm{mM} \mathrm{NaCl}, 1.7 \%$ agar, $2.5 \mathrm{mg} / \mathrm{mL}$ peptone, $5 \mu \mathrm{g} / \mathrm{mL}$ cholesterol, $1 \mathrm{mM} \mathrm{CaCl}, 1 \mathrm{mM} \mathrm{MgSO}_{4}$, and $50 \mathrm{mM} \mathrm{KH}_{2} \mathrm{PO}_{4}$ (pH6.0), at $20^{\circ} \mathrm{C}$. Escherichia coli OP50 was added to each NGM plate as a food source.

\subsection{Preparation of A. annua extract}

$40 \mathrm{~g}$ of A. annua were extracted using hot water extraction with $1.8 \mathrm{~L}$ of distilled water at $80^{\circ} \mathrm{C}$ for $30 \mathrm{~min}$. Cooled extract were then filtered through a $185 \mathrm{~mm}$-filter paper (Advantec, Tokyo, Japan). The second filtering was performed using a $0.2 \mu \mathrm{m}$ bottle-top filter (Nalgene Rapid-Flow Bottle Top Filter, Thermo Scientific, Waltham, USA). A. annua extract were aliquoted and stored at $4{ }^{\circ} \mathrm{C}$.

\subsection{Thermotolerance}

Five L4/young adult worms were transferred to a fresh NGM plate and permitted to lay eggs for $5 \mathrm{~h}$. After removing the five adult worms, the eggs were maintained at $20{ }^{\circ} \mathrm{C}$ for 3 days. Sixty age-synchronized worms were transferred to a fresh NGM plate containing $100 \mu \mathrm{L}$ of different concentrations of $A$. annua $(0,0.1,1,10$, and $100 \%$ of extract) in $5 \mathrm{~mL}$ NGM. 5-fluoro-2'-deoxyuridine (12.5 mg/L; Sigma-Aldrich, St. Louis, USA) was also added to prevent internal hatching. After $24 \mathrm{~h}$, the worms were exposed to heat stress for $10 \mathrm{~h}$ by transferring plates to a $35^{\circ} \mathrm{C}$ incubator. Then, the worms were transferred back to $20^{\circ} \mathrm{C}$. Survival rates after heat stress were monitored $24 \mathrm{~h}$ after.

\subsection{Response to UV irradiation}

Sixty age-synchronized worms were cultured in NGM plates containing different concentrations of $A$. annua for $24 \mathrm{~h}$, as previously mentioned. Then, the plates were incubated in a $254 \mathrm{~nm}-\mathrm{UV}$ crosslinker (BLX-254, VILBER Lourmat Co., Torcy, France) for $1 \mathrm{~min}$ at $20 \mathrm{~J} / \mathrm{cm}^{2} / \mathrm{min}$. After UV irradiation, the plates were transferred back to the $20{ }^{\circ} \mathrm{C}$ incubator. Alive and dead worms were scored every day until all worms were dead.

\subsection{Resistance to oxidative stress}

Age-synchronized young adults worms were treated with A. annua extract in NGM containing 5-fluoro-2'-deoxyruridine for $24 \mathrm{~h}$. Then, the worms were exposed to $2 \mathrm{mM}$ hydrogen peroxide in S-basal without cholesterol ( $5.85 \mathrm{~g}$ sodium chloride, $1 \mathrm{~g}$ potassium phosphate dibasic, and $6 \mathrm{~g}$ potassium phosphate monobasic in $1 \mathrm{~L}$ sterilized distilled-water). The number of dead nematodes was scored after $6 \mathrm{~h}$ of exposure to hydrogen peroxide.

\subsection{GFP expression of stress-responsive genes}

Age-synchronized CL2070 and CF 1553 worms were placed in NGM plates supplemented with A. annua extract at $20^{\circ} \mathrm{C}$ for 9 days. Then, the worms were mounted on a slide glass coated with $2 \%$ agarose and anaesthetized with $1 \mathrm{M}$ sodium azide. After covering the slide with a coverslip, expression of each reporter gene was observed using a confocal microscope (Olympus FV10i, Olympus, Tokyo, Japan). Fluorescence intensity of a randomly selected single worm was quantified with a fluorescence multi-reader (Infinite F200, Tecan, Grodig, Austria).

\subsection{Lifespan assay}

Sixty age-synchronized 3-day-old worms were transferred to fresh NGM plates containing $A$. annua extract and 5-fluoro-2'-deoxyruridine. Thereafter, worms were transferred to fresh NGM plates with $A$. annua extract and 5-fluoro-2'-deoxyruridine every other day. The number of living and dead worms was recorded every day.

\subsection{Statistical analysis}

We employed the log-rank test to analyze the lifespan data. The log-rank test is a non-parametric Mantel-Cox test widely used to compare two time-course survival curves (Peto \& Peto, 1972). Statistical significance in the other experiments was assessed with the standard two-tailed Student's t-test. A p-value lower than 0.05 was regarded as significant.

\section{Results and discussion}

\subsection{Effect of A. annua on response to heat shock and UV irradiation}

Most common environmental stressors encountered during the life cycle includes heat shock and UV irradiation. To reveal the effects of $A$. annua on response to environmental stressors, we examined the survival of worms after heat stress or UV irradiation. Supplementation of $A$. annua extract extended the survival after heat shock. In the wild-type control group, $73.3 \pm 1.92 \%$ (mean of three independent experiments \pm SEM) of worms survived after $10 \mathrm{~h}$ of $35^{\circ} \mathrm{C}$ heat shock. The mean percent survival of worms pre-treated with $100 \%$ A. annua extract significantly increased $(81.1 \pm 1.47 \%, p=0.032)$. However, the dilution of $A$. annua extract failed to show a significant effect on thermotolerance in C. elegans (Figure 1). We also measured the change in resistance to UV irradiation with different concentrations of $A$. annua extract. Unlike the increased survival after heat shock, $A$. annua extract did not affect to resistance to UV irradiation at any concentration of 


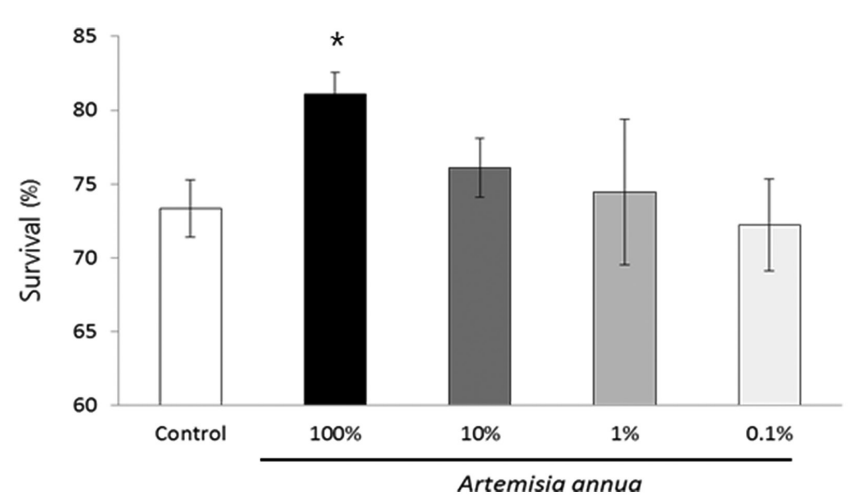

Figure 1. The effects of different concentrations of $A$. annua extract on thermotolerance in C. elegans. Pre-treatment of $100 \%$ A. annua extract significantly increased resistance to heat stress. Values are the mean \pm SEM of three independent experiments $(n=60) .{ }^{*}$ Indicates a significant difference from the control $(p<0.05)$.

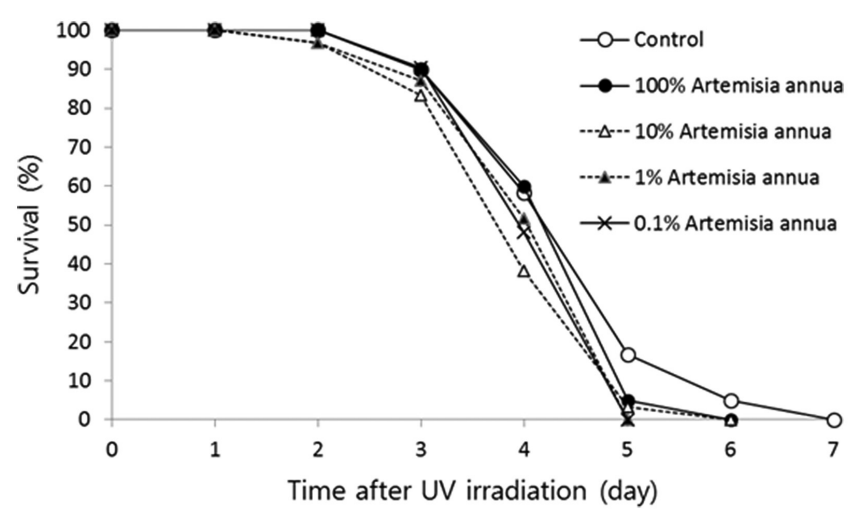

Figure 2. Time-course survival of worms after UV irradiation. In all experimental groups supplemented with different concentrations of A. annua extract, there is no significant difference in survival after UV irradiation compared to the untreated wild-type control.
A. annua extract (Figure 2). Independent replicative experiments also showed no effects on survival after UV irradiation (Table 1). Previous findings show that supplementation of Acanthopanax sessiliflorus extract exhibits an increased resistance to heat stress and UV irradiation in C. elegans (Park et al., 2014). $\mathrm{N}$-acetyl-L-cysteine, a sulfur-containing cysteine derivative with an acetyl group attached to the nitrogen of cysteine, has anti-oxidant and anti-cancer activity (Cai et al., 1999; Yedjou \& Tchounwou, 2007). Survival of worms after heat shock or UV irradiation significantly increases by pre-treatment with $5 \mathrm{mM}$ $\mathrm{N}$-acetyl-L-cysteine (Oh et al., 2015). Our data showed that A. annua can specifically modulate the response to heat stress, however has no effect on resistance to UV irradiation. Further studies identifying cellular components regulated by $A$. annua supplementation will reveal the underlying mechanisms involved in in vivo activities of $A$. annua.

\subsection{Increased resistance to oxidative stress by A. annua}

Environmental and cellular oxidative stress cause detrimental damage to DNA, protein, and lipid molecules and lead to the functional decline of damaged cells and aging of tissues (Martin et al., 1996). We next explored whether the supplementation of $A$. annua affects the oxidative-stress response in C. elegans. Having observed increased resistance to heat stress with $100 \%$ A. annua extract, we compared the survival under oxidative-stress conditions between the untreated wild-type control group and worms pre-treated with $100 \%$ A. annua extract. After $6 \mathrm{~h}$ of hydrogen peroxide treatment, $16.7 \pm 2.36 \%$ (mean of three independent experiments \pm SEM) of worms survived. Supplementation of $A$. annua extract increased the survival under the same oxidative-stress conditions up to $32.5 \pm 3.70 \%(p=0.011)$ (Figure 3 ). These findings demonstrate the anti-oxidant activity of $A$. annua in vivo for the first time. Anti-oxidant activity of natural compounds have been reported in various studies and suggest that it may be a possible therapeutic agent for many diseases, in which oxidative stress is a major causal factor. Resveratrol, a polyphenol compound found in red wine, has

Table 1. Effects of A. annua extract on response to UV irradiation and the lifespan in C. elegans.

\begin{tabular}{|c|c|c|c|}
\hline Assay & Supplementation & Mean survival (day) & $p$-value \\
\hline \multirow{10}{*}{ Resistance to UV irradiation } & Control & 2.8 & \\
\hline & 100\% Artemisia annua & 2.5 & 0.162 \\
\hline & 10\% Artemisia annua & 2.7 & 0.499 \\
\hline & 1\% Artemisia annua & 2.3 & 0.015 \\
\hline & $0.1 \%$ Artemisia annua & 2.4 & 0.021 \\
\hline & Control & 3.7 & \\
\hline & 100\% Artemisia annua & 3.6 & 0.487 \\
\hline & 10\% Artemisia annua & 3.2 & 0.056 \\
\hline & 1\% Artemisia annua & 3.4 & 0.371 \\
\hline & $0.1 \%$ Artemisia annua & 3.4 & 0.19 \\
\hline \multirow{4}{*}{ Lifespan } & Control & 15.8 & \\
\hline & 100\% Artemisia annua & 15.3 & 0.336 \\
\hline & Control & 17.2 & \\
\hline & $100 \%$ Artemisia annua & 17.2 & 0.54 \\
\hline
\end{tabular}

$p$-value was determined using the log-rank test. 
strong anti-oxidant activity and is effective in protecting against cancer, atherosclerosis, and neurodegeneration (Ferguson, 2001; Jang et al., 1997). Curcumin is a major ingredient in yellow curry and has an anti-oxidant activity (Martin-Aragon et al., 1997).

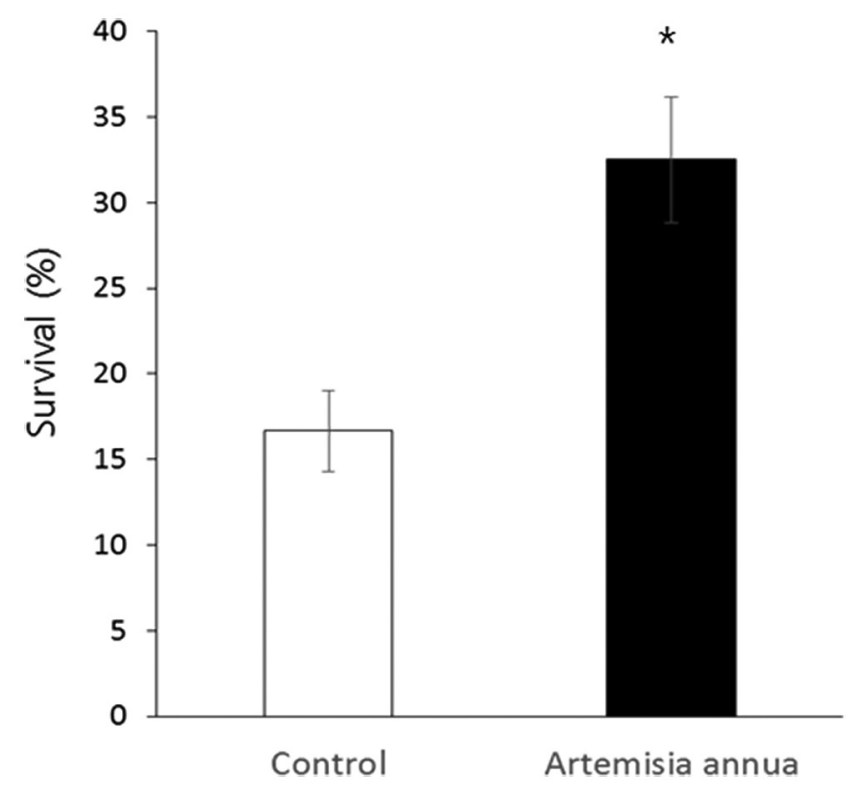

Figure 3. Increased resistance to oxidative stress by A. annua extract in C. elegans. Values are the mean \pm SEM of three independent experiments $(n=60) .{ }^{*}$ Indicates a significant difference from the control $(p<0.05)$.
Curcumin has been used as a traditional medicine in India for the treatment of cancer and gastrointestinal diseases (Kitani et al., 2004). Supplementation of Acanthopanax assiliflorus extract confers increased resistance to oxidative stress in C. elegans (Park et al., 2014). Acanthopanax assiliflorus is a native plant grown in Korea, Japan, and China and is used in diabetes, tumor, and rheumatoid arthritis treatment (Fujikawa et al., 1996). Taken together, our findings indicate that $A$. annua can work as a strong anti-oxidant in vivo and suggest that it may be used to develop novel natural therapeutics for diseases generated by oxidative stress.

\subsection{Induction of stress-responsive genes by A. annua}

Based on our data showing increased resistance to heat and oxidative stress by $A$. annua extract, we monitored the expression level alteration of heat-shock-responsive and anti-oxidant genes caused by $A$. annua extract supplementation. The expression level of $h s p-16.2$ is positively correlated with increased resistance to heat-shock stress and lifespan in C. elegans (Rea et al., 2005). We observed a significant up-regulation of $h s p-16.2$ in worms treated with $100 \%$ A. annua extract (Figure $4 \mathrm{a}$ ). The relative expression of $h s p-16.2$ increased to $138.9 \pm 13.94 \%$ in A. annua-treated worms, compared to the untreated wild-type control $(100.0 \pm 7.30 \%$ ) (Figure $4 \mathrm{~b})$. sod-3 is an anti-oxidant gene involved in the cellular enzymatic defense system against reactive oxygen species (Sánchez-Blanco \& Kim, 2011). As expected from increased resistance to oxidative stress, the expression of

(a)
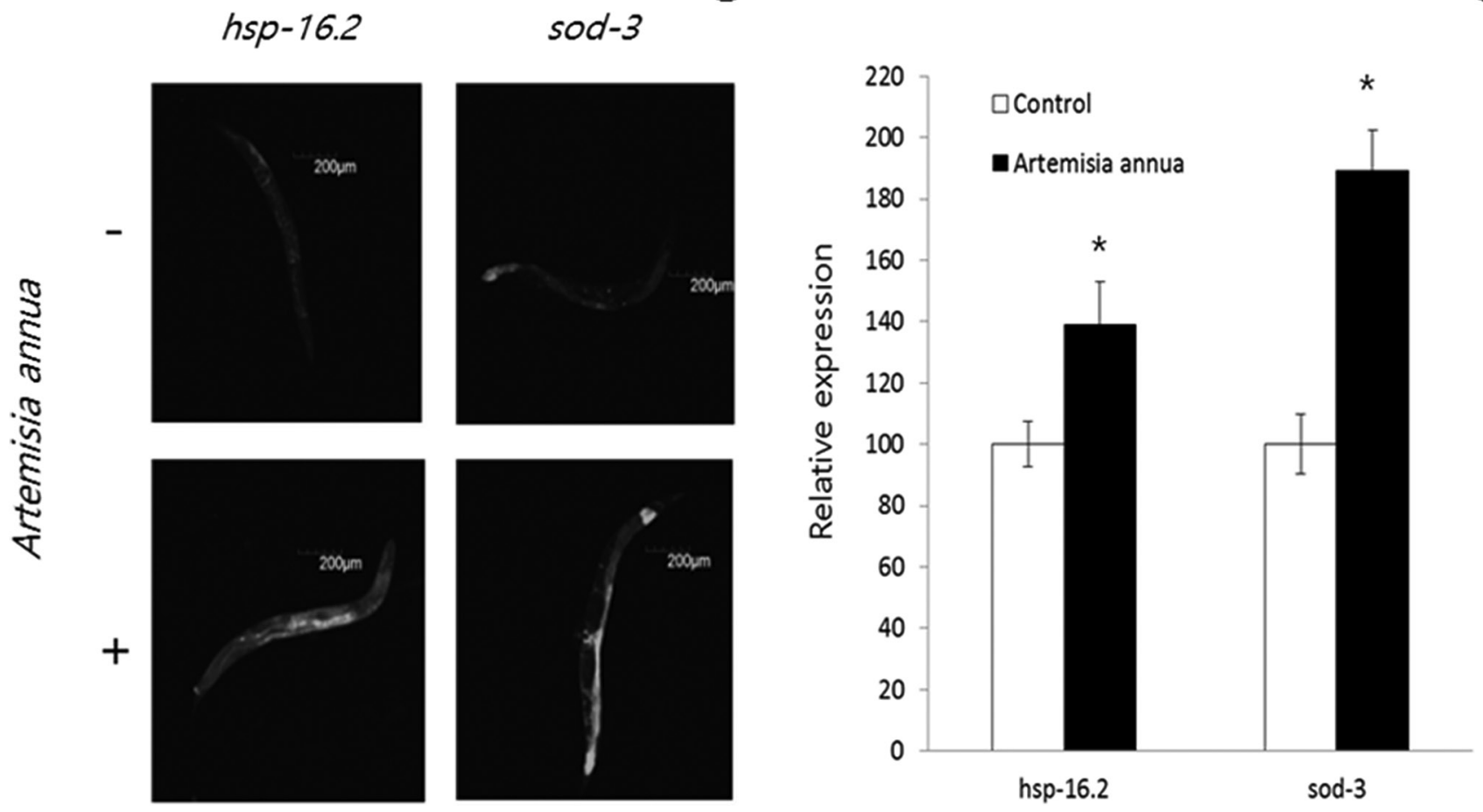

Figure 4. The change in expression of stress-responsive genes by A. annua extract. (a) Total GFP fluorescence of each whole worm was compared between the control and A. annua-treated worms for $h s p-16.2$ and sod-3 genes; (b) GFP fluorescence intensity was quantified with a fluorescence multi-reader $(n=20)$. Values are the mean \pm SEM of three independent experiments. ${ }^{\star}$ Indicates a significant difference from the control $(p<0.05)$. 
sod-3 was induced by A. annua extract (Figure $4 \mathrm{~b}$ ). There was about 1.89 fold increase in expression of sod-3 in worms treated with $100 \%$ A. annua extract, compared to the untreated worms $(p<0.001)$ (Figure $4 \mathrm{~b})$. A recent study shows that dietary supplementation of $\mathrm{N}$-acetyl-L-cysteine results in extended survival time under heat- and oxidative-stress conditions, as well as reduced susceptibility to stresses that accompany the up-regulation of stress-responsive genes (Oh et al., 2015). Gene expression data obtained here support our hypothesis that supplementation of $A$. annua extract confers increased resistance to heat and oxidative stress in vivo and suggests that the underlying mechanisms may be involved with the induction of stress-responsive genes, including heat shock proteins and anti-oxidant genes.

\subsection{Effect of A. annua on lifespan of C. elegans}

Free radical theory of aging suggests that oxidative stress caused by free radicals is one of major factors leading to aging (Harman, 1956). Having observed increased resistance to oxidative stress by $A$. апnua extract, we examined the effect of $A$. annua supplementation on lifespan in C. elegans. As shown in Figure 5, there is no significant difference in both mean and maximum lifespan between the wild-type control and A. annua-treated worms. The mean lifespan in the wild-type control group and worms supplemented with $100 \%$ A. annua extract was 15.8 and 15.3 days, respectively $(p=0.336)$. Independent repeated experiments also failed to show significant effects of $A$. annua on lifespan (Table 1). The effects of genetic or nutritional interventions modulating cellular anti-oxidant defense systems on lifespan remains controversial. In Drosophila melanogaster, the neuronal expression of human SOD-1 extends lifespan (Parkes et al., 1998). Simultaneous over-expression of $\mathrm{Cu} / \mathrm{Zn}$ SOD and CAT increases lifespan in short-lived strains, but not in long-lived strains (Orr et al., 2003; Orr \& Sohal, 1992). Over-expression of anti-oxidant genes, including SOD and CAT, does not induce a longevity phenotype in mice (Chen et al., 2004). Supplementation of Acanthopanax sessiliflorus extract increases resistance to oxidative stress and extends lifespan in C. elegans (Park et al.,

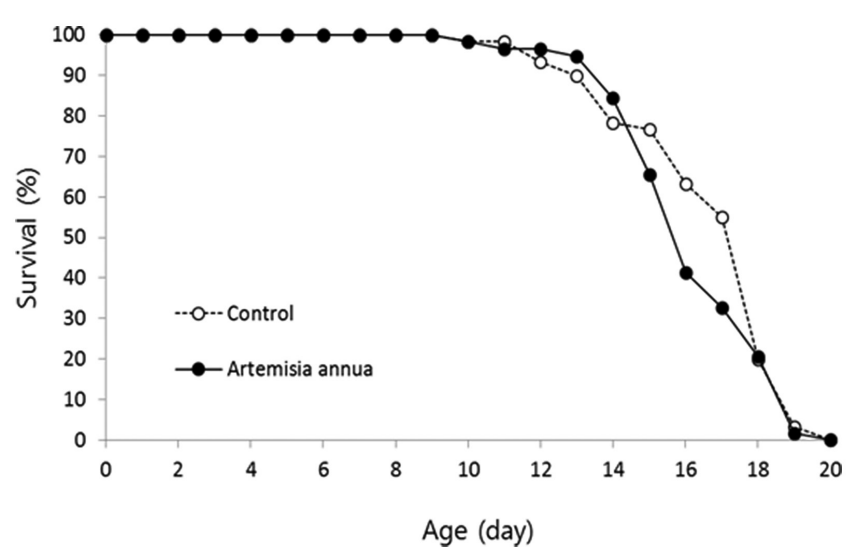

Figure 5. The effect of $A$. annua extract on the lifespan of C. elegans. Both mean and maximum lifespan were unaffected by supplementation with A. annua extract.
2014). Anti-oxidant polyphenols extracted from green tea also show lifespan-extending effects in mice (Kitani et al., 2004). However, dietary intervention with strong anti-oxidants, such as coenzyme $\mathrm{Q}_{10}$ and a-lipoic acid, fails to increase lifespan, although it reduces tumor incidence (Lee et al., 2004).

\section{Conclusions}

In this study, we showed for the first time that $A$. annua extract confers increased resistance to environmental stressors, including heat and oxidative stress, however not to UV irradiation. Dietary supplementation modulates the expression of the stress-responsive genes, $h s p-16.2$ and sod-3, which seem to be the underlying mechanisms of increased resistance to stress. However, anti-oxidant activity of $A$. annua extract did not induce a longevity phenotype. Further studies should focus on the identification of individual active compounds responsible for response to each environmental stresses and possible biological pathways regulated by the supplementation of $A$. annua extract. In addition, the biological data for the effect on diseases other than malaria are necessary for the extension of the therapeutic applications of $A$. annua.

\section{Acknowledgements}

This work was supported by the Soonchunhyang University Research Fund and the Cooperative Research Program for Agriculture Science \& Technology Development (PJ01104602) of the Rural Development Administration, Korea.

\section{References}

Cai, T., Fassina, G., Morini, M., Aluigi, M. G., Masiello, L., Fontanini, G., D’Agostini, F., De Flora, S., Noonan, D. M., \& Albini, A. (1999). $\mathrm{N}$-acetylcysteine inhibits endothelial cell invasion and angiogenesis. Laboratory Investigation, 79(9), 1151-1159. PMid:10496534.

Chen, X., Liang, H., Van Remmen, H., Vijg, J., \& Richardson, A. (2004). Catalase transgenic mice: characterization and sensitivity to oxidative stress. Archives of Biochemistry and Biophysics, 422(2), 197-210. http:// dx.doi.org/10.1016/j.abb.2003.12.023. PMid:14759608.

Ferguson, L. R. (2001). Role of plant polyphenols in genomic stability. Mutation Research, 475(1-2), 89-111. http://dx.doi.org/10.1016/ S0027-5107(01)00073-2. PMid:11295156.

Fujikawa, T., Yamaguchi, A., Morita, I., Takeda, H., \& Nishibe, S. (1996). Protective effects of Acanthopanax senticosus Harms from Hokkaido and its components on gastric ulcer in restrained cold water stressed rats. Biological \& Pharmaceutical Bulletin, 19(9), 1227-1230. http:// dx.doi.org/10.1248/bpb.19.1227. PMid:8889047.

Fukui, K., Omoi, N. O., Hayasaka, T., Shinnkai, T., Suzuki, S., Abe, K., \& Urano, S. (2002). Cognitive impairment of rats caused by oxidative stress and aging, and its prevention by vitamin E. Annals of the New York Academy of Sciences, 959(1), 275-284. http://dx.doi. org/10.1111/j.1749-6632.2002.tb02099.x. PMid:11976202.

Harman, D. (1956). Aging: a theory based on free radical and radiation chemistry. Journal of Gerontology, 11(3), 298-300. http://dx.doi. org/10.1093/geronj/11.3.298. PMid:13332224.

Ho, W. E., Peh, H. Y., Chan, T. K., \& Wong, W. S. (2014). Artemisinins: pharmacological actions beyond anti-malarial. Pharmacology \& Therapeutics, 142(1), 126-139. http://dx.doi.org/10.1016/j. pharmthera.2013.12.001. PMid:24316259. 
Jang, M., Cai, L., Udeani, G. O., Slowing, K. V., Thomas, C. F., Beecher, C. W., Fong, H. H., Farnsworth, N. R., Kinghorn, A. D., Mehta, R. G., Moon, R. C., \& Pezzuto, J. M. (1997). Cancer chemopreventive activity of resveratrol, a natural product derived from grapes. Science, 275(5297), 218-220. http://dx.doi.org/10.1126/science.275.5297.218. PMid:8985016.

Kitani, K., Yokozawa, T., \& Osawa, T. (2004). Interventions in aging and age-associated pathologies by means of nutritional approaches. Annals of the New York Academy of Sciences, 1019(1), 424-426. http:// dx.doi.org/10.1196/annals.1297.075. PMid:15247057.

Kokoszka, J. E., Coskun, P., Esposito, L. A., \& Wallace, D. C. (2001). Increased mitochondrial oxidative stress in the Sod2 (+/-) mouse results in the age-related decline of mitochondrial function culminating in increased apoptosis. Proceedings of the National Academy of Sciences of the United States of America, 98(5), 2278-2283. http:// dx.doi.org/10.1073/pnas.051627098. PMid:11226230.

Lee, C. K., Pugh, T. D., Klopp, R. G., Edwards, J., Allison, D. B., Weindruch, R., \& Prolla, T. A. (2004). The impact of alpha-lipoic acid, coenzyme Q10 and caloric restriction on life span and gene expression patterns in mice. Free Radical Biology \& Medicine, 36(8), 1043-1057. http://dx.doi.org/10.1016/j.freeradbiomed.2004.01.015. PMid:15059645.

Lipman, R. D., Bronson, R. T., Wu, D., Smith, D. E., Prior, R., Cao, G., Han, S. N., Martin, K. R., Meydani, S. N., \& Meydani, M. (1998). Disease incidence and longevity are unaltered by dietary antioxidant supplementation initiated during middle age in C57BL/6 mice. Mechanisms of Ageing and Development, 103(3), 269-284. http:// dx.doi.org/10.1016/S0047-6374(98)00048-7. PMid:9723903.

Martin, G. M., Austad, S. N., \& Johnson, T. E. (1996). Genetic analysis of ageing: role of oxidative damage and environmental stresses. Nature Genetics, 13(1), 25-34. http://dx.doi.org/10.1038/ng059625. PMid:8673100.

Martin-Aragon, S., Benedi, J. M., \& Villar, A. M. (1997). Modifications on antioxidant capacity and lipid peroxidation in mice under fraxetin treatment. Journal of Pharmaceutics \& Pharmacology, 49(1), 49-52. http://dx.doi.org/10.1111/j.2042-7158.1997.tb06751.x. PMid:9120770.

Miquel, J. (2001). Nutrition and ageing. Public Health Nutrition, 4(6A), 1385-1388. http://dx.doi.org/10.1079/PHN2001224. PMid:11918486.

Navarro, A., Gomez, C., Sanchez-Pino, M. J., Gonzalez, H., Bandez, M. J., Boveris, A. D., \& Boveris, A. (2005). Vitamin E at high doses improves survival, neurological performance, and brain mitochondrial function in aging male mice. American Journal of Physiology. Regulatory, Integrative and Comparative Physiology, 289(5), R1392-R1399. http://dx.doi.org/10.1152/ajpregu.00834.2004. PMid:16020519.

Oh, S. I., Park, J. K., \& Park, S. K. (2015). Lifespan extension and increased resistance to environmental stressors by $\mathrm{N}$-acetyl-Lcysteine in Caenorhabditis elegans. Clinics, 70(5), 380-386. http:// dx.doi.org/10.6061/clinics/2015(05)13. PMid:26039957.

Orr, W. C., \& Sohal, R. S. (1992). The effects of catalase gene overexpression on life span and resistance to oxidative stress in transgenic Drosophila melanogaster. Archives of Biochemistry and Biophysics, 297(1), 35-41. http://dx.doi.org/10.1016/0003-9861(92)90637-C. PMid:1379030.

Orr, W. C., Mockett, R. J., Benes, J. J., \& Sohal, R. S. (2003). Effects of overexpression of copper-zinc and manganese superoxide dismutases, catalase, and thioredoxin reductase genes on longevity in Drosophila melanogaster. The Journal of Biological Chemistry, 278(29), 2641826422. http://dx.doi.org/10.1074/jbc.M303095200. PMid:12743125.

Park, J. K., Kim, C. K., Gong, S. K., Yu, A. R., Lee, M. Y., \& Park, S. K. (2014). Acanthopanax sessiliflorus stem confers increased resistance to environmental stresses and lifespan extension in Caenorhabditis elegans. Nutrition Research and Practice, 8(5), 526-532. http://dx.doi. org/10.4162/nrp.2014.8.5.526. PMid:25324932.

Park, S. K., \& Park, S. K. (2013). Electrolyzed-reduced water increases resistance to oxidative stress, fertility, and lifespan via insulin/IGF1-like signal in C. elegans. Biological Research, 46(2), 147-152. http:// dx.doi.org/10.4067/S0716-97602013000200005. PMid:23959012.

Park, S. K., Kim, J. J., Yu, A. R., Lee, M. Y., \& Park, S. K. (2012). Electrolyzedreduced water confers increased resistance to environmental stresses. Molecular and Cellular Toxicology, 8(3), 241-247. http://dx.doi. org/10.1007/s13273-012-0029-1.

Parkes, T. L., Elia, A. J., Dickinson, D., Hilliker, A. J., Phillips, J. P., \& Boulianne, G. L. (1998). Extension of Drosophila lifespan by overexpression of human SOD1 in motorneurons. Nature Genetics, 19(2), 171-174. http://dx.doi.org/10.1038/534. PMid:9620775.

Peto, R., \& Peto, J. (1972). Asymptotically efficient rank invarient test procedures. Journal of the Royal Statistical Society Series A: General, 135(2), 185-207. http://dx.doi.org/10.2307/2344317.

Rea, S. L., Wu, D., Cypser, J. R., Vaupel, J. W., \& Johnson, T. E. (2005). A stress-sensitive reporter predicts longevity in isogenic populations of Caenorhabditis elegans. Nature Genetics, 37(8), 894-898. http:// dx.doi.org/10.1038/ng1608. PMid:16041374.

Sánchez-Blanco, A., \& Kim, S. K. (2011). Variable pathogenicity determines individual lifespan in Caenorhabditis elegans. PLOS Genetics, 7(4), e1002047. http://dx.doi.org/10.1371/journal. pgen.1002047. PMid:21533182.

Sohal, R. S., \& Weindruch, R. (1996). Oxidative stress, caloric restriction, and aging. Science, 273(5271), 59-63. http://dx.doi.org/10.1126/ science.273.5271.59. PMid:8658196.

Sohal, R. S., Agarwal, A., Agarwal, S., \& Orr, W. C. (1995). Simultaneous overexpression of copper- and zinc-containing superoxide dismutase and catalase retards age-related oxidative damage and increases metabolic potential in Drosophila melanogaster. The Journal of Biological Chemistry, 270(26), 15671-15674. http://dx.doi.org/10.1074/ jbc.270.26.15671. PMid:7797567.

Song, Y., Desta, K. T., Kim, G. S., Lee, S. J., Lee, W. S., Kim, Y. H., Jin, J. S., Abd El-Aty, A. M., Shin, H. C., Shim, J. H., \& Shin, S. C. (2016). Polyphenolic profile and antioxidant effects of various parts of Artemisia annua L. Biomedical Chromatography, 30(4), 588-595. http://dx.doi.org/10.1002/bmc.3587. PMid:26285146.

Sun, J., \& Tower, J. (1999). FLP recombinase-mediated induction of Cu/ $\mathrm{Zn}$-superoxide dismutase transgene expression can extend the life span of adult Drosophila melanogaster flies. Molecular and Cellular Biology, 19(1), 216-228. http://dx.doi.org/10.1128/MCB.19.1.216. PMid:9858546.

Wei, Y. H., \& Lee, H. C. (2002). Oxidative stress, mitochondrial DNA mutation, and impairment of antioxidant enzymes in aging. Experimental Biology and Medicine, 227(9), 671-682. PMid:12324649.

Yedjou, C. G., \& Tchounwou, P. B. (2007). N-acetyl-l-cysteine affords protection against lead-induced cytotoxicity and oxidative stress in human liver carcinoma (HepG2) cells. International Journal of Environmental Research and Public Health, 4(2), 132-137. http:// dx.doi.org/10.3390/ijerph2007040007. PMid:17617676. 